
3 Research Square
Preprints are preliminary reports that have not undergone peer review.
They should not be considered conclusive, used to inform clinical practice, or referenced by the media as validated information.

\title{
The Extent of Community Pharmacists' Involvement in Detecting and Resolving Drug Related Problems (DRPs) in Prescriptions - A Cross Sectional Study in a Community Pharmacy Setting From Sri Lanka
}

Tharmalinga Sharma Jegath Janani

University of Sri Jayewardenepura

Rafaideen Risla

University of Sri Jayewardenepura

Lelwala Guruge Thushani Shanika

University of Sri Jayewardenepura

Nithushi Rajitha Samaranayake ( $\nabla$ nithushi@sjp.ac.lk)

University of Sri Jayewardenepura

\section{Research Article}

Keywords: Community Pharmacists, Drug Related Problems, Medication Safety, Prescriptions

Posted Date: November 25th, 2020

DOI: https://doi.org/10.21203/rs.3.rs-109512/v1

License: () (1) This work is licensed under a Creative Commons Attribution 4.0 International License. Read Full License 


\section{Abstract}

Background: Drug Related Problems (DRPs) in prescriptions could harm patients.

Purpose: To assess, the prevalence of DRPs in prescriptions, and the ability of community pharmacists to detect and correct DRPs in prescriptions dispensed in a selected community pharmacy.

Methods: A prospective, cross-sectional study was conducted in a selected community pharmacy in Colombo, Sri Lanka, where one researcher reviewed for DRPs in systematically selected prescriptions $(\mathrm{N}=400)$, and another directly observed the proportion of DRPs identified by community pharmacists in the same set of prescriptions. Actions taken by pharmacists on resolving DRPs were also documented. DRPs were classified according to a slightly modified version of Pharmaceutical Care Network Europe classification V8.01.

Results: Among 1986 drugs, 1211 DRPs were identified by researchers, and 441 by community pharmacists ( $N=24)$. Drug selection ( $N=15)$, dose selection $(\mathrm{N}=817)$, duration of treatment $(\mathrm{N}=128)$, incomplete prescriptions $(\mathrm{N}=128)$, and in-house classification such as outdated prescriptions, missing unit of measurements, and ambiguous names of medicines that cannot be read by both community pharmacists and researcher ( $\mathrm{N}=122)$ were the most common DRPs identified by researchers, of which only $1(p<0.001), 394(p<0.001), 13(p=0.006), 5(p<0.001)$, and 27 ( $p<0.001)$ respectively were identified by pharmacists. DRP identification by researcher and pharmacist did not significantly differ for inappropriate drug form ( $p=0.550)$. Among $441 \mathrm{DRPs}$ identified by pharmacists, 406 were corrected by them $(p=0.92)$. Most DRPs were self-resolved by pharmacists themselves $(366 / 406)(p=0.90)$, while patients were also sent back to prescriber $(14 / 406)(p=0.03)$ and refused to dispense drugs $(9 / 406)(p=0.02)$.

Conclusion: Among DRPs frequently observed in prescriptions in the community, pharmacists missed some, including incomplete prescriptions that had potential to harm. Pharmacist resolved most of the DRPs detected.

\section{Background}

Medicines are given to treat diseases, however inappropriate prescription could lead to Drug Related Problems (DRPs) [14,15,24]. DRPs are known to be a global issue [2,23]. DRPs can cause significant risks to patients and may adversely affect quality of life, increase mortality, morbidity rates, lead to permanent disabilities and life-threatening effects in patients $[2,8,18,23,26]$. DRPs could also have a great impact on healthcare costs $[9,12,13,14,21]$. The Pharmaceutical Care Network Europe (PCNE) classifies a DRP as "an event or circumstance involving drug treatment that actually or potentially interferes with the patients' desired health outcomes" [7].

Several studies have shown that DRPs are prevalent in the community $[9,18]$. A study from USA reported that $25 \%$ of patients in the community experienced an adverse event within 4 weeks of receiving a prescription [8], while an Indian study revealed that DRPs were prevalent in a community pharmacy setting at a rate of $41.8 \%$, where $10 \%$ were severe and $41 \%$ were moderately severe DRPs resulting in primary consultation and hospitalization [1].

Community pharmacists are the most accessible by the public and last accountable healthcare professionals who can identify and correct DRPs in outpatient prescriptions before a patient is harmed by them [28]. A study was done to observe the extent to which pharmacist can participate in reducing the incidences of DRPs in Lahore, Pakistan and found that although different types of DRPs were identified by pharmacists, only $37 \%$ of pharmacists intervened to reduce the incidence of DRPs. Most of the pharmacists were knowledgeable about DRPs but refrained from actively resolving DRPs due to their lack of acceptance by society and other healthcare professionals in this task, lack of a proper reporting system, lack of incentives, and lack of time due to administrative responsibilities especially in retail pharmacy[10]. These findings could be related to most countries in the South Asian region where pharmacists are submissive in challenging a problem detected in prescriptions.

In developed countries, community pharmacists' role is integrated into the healthcare system and well recognised by the public [22]. In Sri Lanka, community pharmacists dispense prescriptions prescribed by medical practitioners working in different levels of care including general practitioners and specialized consultants, in both State and private hospitals. Given this responsibility, community pharmacists should be able to identify the diverse and frequent occurrences of DRPs in prescriptions and be assertive in resolving them. There are very little published research findings reported regarding DRPs and the few reported are based on in-patients [25,26] or specific clinics in Sri Lanka [16]. Although these studies have contributed some evidence on DRPs prevalent in Sri Lanka, little is known on community prescriptions and the involvement of community pharmacists in detecting and resolving DRPs in prescriptions.

To bridge this gap, we conducted the following study to assess the nature and frequency of DRPs present in prescriptions dispensed, the proportion of DRPs identified by community pharmacists and the types of corrective action taken by community pharmacists when DRPs were detected in prescriptions dispensed at a selected community pharmacy in the Colombo district.

\section{Methods}

Study Design and Settings

A prospective, cross-sectional study was conducted in a selected community pharmacy in the Colombo District over a period of four months (November 29 , 2017 to March 30,2018). The selected community pharmacy is an outlet of the only State-owned pharmacy chain in Sri Lanka which operates 24 hours a day for 365 days of the year and serves around 600 patients a day. The study pharmacy receives prescriptions from about 10 public and private hospitals situated in the vicinity.

Study Participants

Page 2/11 
All community pharmacists registered at the Sri Lanka Medical Council (SLMC) and working at the study setting were observed while training pharmacists were excluded from the study.

Sample Size Calculation

The number of prescriptions to be reviewed was calculated using an online sample size calculator (www.raosoft.com) considering a $95 \%$ confidence level, $5 \%$ significance level and $50 \%$ response distribution. The calculated number of prescriptions was 384 but 400 prescriptions were selected considering a $10 \%$ dropout of prescriptions during analysis.

Study Instruments

Prescription review and direct observation methods were used in this study. All the DRPs were classified according to a slightly modified version of the PCNE classification V8.01 (Additional file 1). The in-house modification to the PCNE classification included, addition of two sub-sections under 'causes'; "Incomplete essential information in prescriptions"; (Necessary information not provided including age of the patient, date, and SLMC registration number of prescriber) and "Other cause"; (Outdated prescription, unit of strength of the drug missing, and ambiguously written names of medicine that cannot be read by pharmacists).

A pilot study was conducted among 10 prescriptions after obtaining ethics approval and permission from the relevant study pharmacy. The pre-determined data collection format was fine-tuned according to the pilot study.

Study Process

Two researchers visited the pharmacy every four days of a week (during week or weekends) and selected to observe the dispensing process of every $5^{\text {th }}$ prescription until the calculated sample size was achieved. If the selected prescription did not have at least one oral medicine, the prescription next in line was observed. This prescription information was transferred on to the predetermined data collection sheet (Additional file 2).

We directly observed the complete dispensing cycle of the selected prescriptions and monitored whether the pharmacists were able to identify any DRPs. We also observed the actions taken by pharmacists to correct the problem when DRPs were detected. This information was transferred on to the predetermined data collection sheet (Additional file 3).

Two researchers retrospectively reviewed the same set of prescriptions in order to assess DRPs actually present in them. Standard references such as the, British National Formulary (BNF) -70 [11], Australian Medicines Handbook (AMH) - 2011 [4], Medscape Pharmacists [17] were used to identify the DRPs. All DRPs identified were endorsed by two senior academic pharmacists. Study process is shown in Figure I.

Consent and Confidentiality

At the beginning of the study, pharmacists were informed about the intentions of the study, and written informed consent was obtained. The respondents were assured about the confidentiality of data and personal identifiers. Researchers refrained from discussing about DRPs detected by them with pharmacist and patients but DRPs with potential to harm patients were informed to supervisors for necessary action.

Ethics Approval

The Ethics Review Committee, Faculty of Medical Sciences, University of Sri Jayewardenepura approved this study (Reference number: B.Pharm/08/17, Date: $20^{\text {th }}$ of November 2017). Approval was also obtained from the Head office of the community pharmacy chain to conduct this study.

Data Analysis

All the data were fed into a database using SPSS, V.21 (IBM, Chicago, USA), and cleaned to assure the quality of the entered data. For descriptive data, continuous variables were expressed as mean \pm standard deviations (SD) and frequencies (Numbers and \%). For all tests, a p<0.05 was considered to be statistically significant. Sample proportion tests in Minitab 14 was used to compare proportions of DRPs identified by researchers and community pharmacists.

\section{Results}

Four hundred prescriptions containing 1986 drugs were analysed. The researchers identified $14(13.5 \%, 14 / 400)$ prescriptions with no DRPs and 346 (86.5 \%, $346 / 400)$ prescriptions with at least one DRP. A mean number of $5.0( \pm 2.6)$ drugs per prescription was prescribed with a minimum of one and a maximum of 13 drugs per prescription.

Twenty-four community pharmacists employed at the outlet of the selected pharmacy chain participated in the study. The mean age of participants was $36.7 \pm$ 9.1 years and $66.7 \%$ were women. Demographics of patients owning the prescription are shown in Table 1 and demographics of participating pharmacists are shown in Table 2.

Table 1 Demographic characteristics of patients owning the prescriptions $(\mathrm{N}=400)$ 


\begin{tabular}{|ll|}
\hline Characteristics & Outcome \\
Mean age (SD) & $56.5( \pm 18.2)$ \\
$<20$ & \\
$21-40$ & $19(4.8)$ \\
$41-60$ & $34(8.5)$ \\
$61-80$ & $110(27.5)$ \\
$>80$ & $144(36)$ \\
\hline Institution prescriptions obtained from, N (\%) & Outcome \\
Private hospital & $215(53.8)$ \\
State hospital & $134(33.5)$ \\
General practitioners (Private practitioner) & $51(12.8)$ \\
\hline
\end{tabular}

SD standard deviation

Table 2 Demographic characteristics of community pharmacists $(\mathrm{N}=24)$

\begin{tabular}{|ll|}
\hline Characteristics & Outcome \\
Gender, N (\%) & $8(33.3)$ \\
Men & $16(66.7)$ \\
Women & $36.7( \pm 9.1)$ \\
Mean age (SD) & \\
Age groups in years, N (\%) & $15(62.5)$ \\
$21-40$ & $9(37.5)$ \\
$41-60$ & - \\
$61-80$ & $8.3( \pm 6.3)$ \\
\hline Mean number of years working as a registered pharmacist (SD)
\end{tabular}

SD standard deviation

Among 1986 drugs analysed (400 prescriptions), a total of 1211 DRPs were detected by researchers whereas only 441 (36.4\%, 441/1211) DRPs were detected by community pharmacists. Proportions of DRPs identified by researcher and community pharmacists were compared and is shown in Table 3 . Categories, subcategories, and examples for DRPs are also shown in Table 3.

\section{Types of DRPs which were not identified by community pharmacists}

Fourteen out of 15 drug selection errors identified by researchers were missed by pharmacists. There were ten duplications of medicines identified by researchers of which only one duplication was identified by community pharmacists. Among dose selection errors, wrong/unclear/missing dose timing errors were the highest DRP sub-type identified by researchers $(\mathrm{N}=525)$ of which 160 were missed by community pharmacists. However, strength of the drug missing was the highest DRP sub type missed by community pharmacists $(\mathrm{N}=214)$.

\section{Different types of corrective action taken by community pharmacists to resolve identified DRPs}

Among 441 DRPs identified by community pharmacists, 406 were corrected. Most of the DRPs were corrected by community pharmacists themselves without resorting to the prescriber (self-resolved) ( $\mathrm{N}=366 / 406 ; 90.1 \%)$. The next most frequent corrective actions taken were, sending the patient back to the prescriber to clarify the detected problem ( $N=14 / 406 ; 3.4 \%)$, and refusing to dispense the drug $(\mathrm{N}=9 / 406 ; 2.2 \%)$. A summary of corrective actions taken by community pharmacists for DRPs identified by them are shown in Figure 2 and types of corrective action taken by community pharmacists categorized by the types of DRPs are also shown in Table 4.

Table 3 Categories and subcategories of drug related problems (DRPs) identified by researchers and community pharmacists 


\begin{tabular}{|c|c|c|c|c|c|c|}
\hline \multirow{3}{*}{ DRP categories and subcategories } & \multicolumn{5}{|c|}{ DRPs identified by } & \multirow[t]{3}{*}{ Examples } \\
\hline & \multicolumn{2}{|c|}{$\begin{array}{l}\text { Researchers } \\
(\mathrm{N}=1211)\end{array}$} & \multicolumn{2}{|c|}{$\begin{array}{l}\text { Community } \\
\text { pharmacists } \\
(\mathrm{N}=441)\end{array}$} & \multirow[t]{2}{*}{ P value* } & \\
\hline & $\mathbf{N}$ & (\%) & $\mathbf{N}$ & (\%) & & \\
\hline Drug selection & 15 & 1.2 & 1 & 0.2 & 0.010 & \\
\hline Inappropriate combination of drugs & 5 & 0.4 & 0 & 0 & 0.025 & $\begin{array}{l}\text { Atenolol and verapamil } \\
\text { Theophylline and clarithromycin }\end{array}$ \\
\hline $\begin{array}{l}\text { Inappropriate duplication of therapeutic group or active } \\
\text { ingredient }\end{array}$ & 10 & 0.8 & 1 & 0.2 & 0.082 & $\begin{array}{l}\text { Celecoxib and etoricoxib } \\
\text { Atorvastatin and rosuvastatin }\end{array}$ \\
\hline $\begin{array}{l}\text { Drug form } \\
\text { Inappropriate drug form }\end{array}$ & $\begin{array}{l}1 \\
1\end{array}$ & $\begin{array}{l}0.08 \\
0.08\end{array}$ & $\begin{array}{l}1 \\
1\end{array}$ & $\begin{array}{l}0.2 \\
0.2\end{array}$ & $\begin{array}{l}0.550 \\
0.550\end{array}$ & $\begin{array}{l}\text { Capsule amoxicillin prescribed instead of } \\
\text { syrup amoxicillin for a three-month-old baby }\end{array}$ \\
\hline $\begin{array}{l}\text { Dose selection } \\
\text { Drug dose too high }\end{array}$ & 817 & 67.4 & 394 & 89.3 & $<0.001$ & \\
\hline $\begin{array}{l}\text { 1. Drug dose too high because the wrong dose was written } \\
\text { by a prescriber }\end{array}$ & 3 & 0.2 & 3 & 0.7 & 0.299 & $\begin{array}{l}\text { Sertraline } 125 \mathrm{mg} \text { prescribed instead of } \\
\text { sertraline } 12.5 \mathrm{mg} \text { (previously taking a dose of } \\
12.5 \mathrm{mg} \text { ) } \\
\text { Thyroxine } 50 \mathrm{mg} \text { prescribed instead of } \\
\text { Thyroxine } 50 \text { micrograms }\end{array}$ \\
\hline $\begin{array}{l}\text { 2. Drug dose too high because the wrong dose unit was } \\
\text { written by a prescriber }\end{array}$ & 2 & 0.1 & 2 & 0.5 & 0.397 & $\begin{array}{l}\text { Losartan prescribed in three divided doses per } \\
\text { day }\end{array}$ \\
\hline $\begin{array}{l}\text { Dosage regimen too frequent } \\
\text { Dose timing instructions wrong, unclear or missing }\end{array}$ & 23 & 1.9 & 0 & 0 & $<0.001$ & $\begin{array}{l}\text { Thyroxine, alendronate administration timing } \\
\text { was missing } \\
\text { 'Losartan 1-tab bd' was written on prescription } \\
\text { Only 'captopril } 25 \mathrm{mg} \text { ' was written on } \\
\text { prescription }\end{array}$ \\
\hline Strength of the drug missing & 525 & 43.3 & 365 & 82.7 & $<0.001$ & \\
\hline Frequency of the drug administration missing & 217 & 17.9 & 3 & 0.7 & $<0.001$ & $\begin{array}{l}\text { Duration was written as one year for } \\
\text { amlodipine, prazosin, bisoprolol, metformin, } \\
\text { gliclazide, sitagliptin and isophane insulin in a } \\
\text { prescription }\end{array}$ \\
\hline Dunations & 128 & 10.5 & 13 & 2.9 & $\begin{array}{l}0.446 \\
<0.001\end{array}$ & $\begin{array}{l}\text { Duration was not written for clarithromycin } \\
\text { and amoxicillin }\end{array}$ \\
\hline Duration of treatment missing & 116 & 0.9 & 4 & (n) & $\begin{array}{l}0.875 \\
\\
<0.001\end{array}$ & \\
\hline
\end{tabular}


Incomplete essential information in prescriptions (in-house)

Necessary information not provided (includes the age of patient, date, and Sri Lanka Medical Council registration

number of prescriber)

Outdated prescription

Unit of drug strength missing

Ambiguous name of medicine that

cannot be read by both community

pharmacists and researcher

*Comparison of proportions of DRPs identified by researcher and pharmacist

Table 4 Types of corrective action taken by community pharmacists categorized by types of DRPs

\section{$\begin{array}{lllll}122 & 10.0 & 27 & 6.1 & 0.006\end{array}$}

$\begin{array}{llllll}34 & 2.8 & 17 & 3.8 & 0.310 \\ 79 & 6.5 & 1 & 2.0 & <0.001 \\ 9 & 0.7 & 9 & 0.2 & 0.070\end{array}$

$<0.001$

$<0.001$ 


\begin{tabular}{|c|c|c|c|c|c|c|c|c|c|c|c|}
\hline & $\begin{array}{l}\text { Duplication } \\
\text { of drugs }\end{array}$ & $\begin{array}{l}\text { Inappropriate } \\
\text { drug form }\end{array}$ & $\begin{array}{l}\text { Drug } \\
\text { dose } \\
\text { too } \\
\text { high }\end{array}$ & $\begin{array}{l}\text { Duration } \\
\text { missing }\end{array}$ & $\begin{array}{l}\text { Duration } \\
\text { of } \\
\text { treatment } \\
\text { too long }\end{array}$ & $\begin{array}{l}\text { Strength } \\
\text { of the } \\
\text { drug } \\
\text { missing }\end{array}$ & $\begin{array}{l}\text { Frequency } \\
\text { of drug } \\
\text { missing }\end{array}$ & $\begin{array}{l}\text { Reg. no } \\
\text { of } \\
\text { prescriber } \\
\text { missing }\end{array}$ & $\begin{array}{l}\text { Outdated } \\
\text { prescription }\end{array}$ & $\begin{array}{l}\text { Strength } \\
\text { unit of } \\
\text { the drug } \\
\text { missing }\end{array}$ & $\begin{array}{l}\text { Ambiguou: } \\
\text { name of } \\
\text { medicine } \\
\text { that canno } \\
\text { be read by } \\
\text { pharmacis }\end{array}$ \\
\hline $\begin{array}{l}\text { Checking } \\
\text { the recent } \\
\text { medical } \\
\text { history of } \\
\text { the patient }\end{array}$ & & & & & & & 4 & & & & \\
\hline $\begin{array}{l}\text { Sending } \\
\text { back the } \\
\text { patient to } \\
\text { prescriber }\end{array}$ & & & 2 & & & 1 & 3 & & & & 8 \\
\hline $\begin{array}{l}\text { Discussing } \\
\text { the issue } \\
\text { with a } \\
\text { patient to } \\
\text { clarify a } \\
\text { DRP } \\
\text { (verbally) }\end{array}$ & 1 & & & & & & 6 & & & & 1 \\
\hline $\begin{array}{l}\text { Self- } \\
\text { resolved } \\
\text { without } \\
\text { checking } \\
\text { any related } \\
\text { references }\end{array}$ & & & 1 & & & & & & & 1 & \\
\hline $\begin{array}{l}\text { Refusing } \\
\text { to } \\
\text { dispense } \\
\text { the drug }\end{array}$ & & & 1 & & & & & 4 & 3 & & 1 \\
\hline $\begin{array}{l}\text { Discussing } \\
\text { with other } \\
\text { staff to } \\
\text { clarify the } \\
\text { problem }\end{array}$ & & 1 & 1 & & & 1 & & & 1 & & 1 \\
\hline \multicolumn{12}{|l|}{$\begin{array}{l}\text { Consulting } \\
\text { a written } \\
\text { reference } \\
\text { material or } \\
\text { decision } \\
\text { support } \\
\text { software }\end{array}$} \\
\hline $\begin{array}{l}\text { No action } \\
\text { taken }\end{array}$ & & & & 9 & 4 & & 8 & 1 & 13 & & \\
\hline
\end{tabular}

\section{Discussion}

This study found that DRPs exist in prescriptions dispensed in the community $(86.5 \%, 346 / 400)$ and community pharmacists identified and resolved some of them $(36.4 \%, 441 / 1211$, and $33.5 \%, 406 / 1211$ respectively). Community pharmacists identified wrong doses, frequencies, dosage forms and durations of drugs written on prescriptions. However, they overlooked DRPs related to missing information, drug duplications, and drug interactions. Pharmacists also resolved most of the DRPs identified (406/441) using self-judgement (366/406). Patients were sent back to prescriber (14/406) and refused dispensation $(9 / 406)$ in some cases.

During the study period, we reported a DRP rate of $86.5 \%$ which is considerably higher than DRPs reported in other studies. Although most DRPs may not end up in immediate clinical consequences, they could lead to poor compliance and sub-therapeutic effects in the long run. In a study done in Europe: Austria, Denmark, Germany, The Netherlands, Portugal and Spain, Paulino et al., reported a total of 451 DRPs in 277 (out of 435) prescriptions (63.7\%) [19] and a study conducted in India reported 90 DRPs among 215 prescriptions (41.8\%) [1]. It is difficult to directly compare findings of this study with other international studies due to the explicit DRP definitions we used to capture even trivial issues in prescriptions. However, the fact that more than $80 \%$ of prescriptions had at least one DRP is similar to results reported from the West (18\% to $88 \%$ of patients) [13]. However, it should be noted that the number of identified DRPs depend on multiple factors including study design, type of settings, study population, classification system used and the denominator used for statistical analysis.

There were $17.9 \%(217 / 1211)$ of drugs where the strength was not indicated on the prescriptions and was prescribed as ' 1 tab' or ' 2 tab' and the community pharmacist resolved to dispense the lowest strength available. Although unnecessary overdosing and toxicities may be avoided, selecting the lowest strength 
option could result in therapeutic failure if the prescriber had intended a higher dose. Drug selection was the next most common problem identified in this study of which 10 out of 15 inappropriate combinations and drug duplications identified were potentially harmful. A previous prospective, cohort study conducted in two Sri Lankan medical wards to evaluate medication appropriateness, also reported a rate of $1.7 \%$ drug duplications [20]. In this study the most likely reason for drug duplications was prescribing in brand names. Pharmacists need to be advocated on identification of DRPs, even the potential issues that could result in harm, and on prioritizing for corrective actions.

There were inappropriate abbreviations observed in this sample of prescriptions, but these were not included as DRPs in the analysis. Inappropriate abbreviations were used to indicate frequency (' $d$ ' to denote daily, ' $m$ ' to denote mane, ' $n$ ' to denote nocte), drug name (HCT to denote hydrochlorothiazide, CBZ to denote carbamazepine and HCQ to denote hydroxychloroquine) and dose units of drugs (mcg to denote microgram and IU to denote International Unit). Previous studies too have reported the prevalence of non-standard abbreviations and incomplete units used in Sri Lankan prescriptions [6].

It is encouraging to note that, community pharmacists in this study had taken corrective actions for $92 \%$ of the DRPs detected by them. Other published studies indicate that, counselling and reassuring patients, followed by practical instructions, were by far the most common types of interventions used by pharmacists when resolving DRPs $[19,27]$. This practice was not frequently seen in our study but self-resolving of DRP was frequently observed instead. It is important to give clear instructions to patients on dose timing and strength, for drugs like thyroxine, warfarin, alendronate, methotrexate, proton pump inhibitors and anti-diabetes drugs are often associated with significant drug-drug and food-drug interactions. We observed that most of these instructions were not clearly indicated in prescriptions. Often important drug related instructions were given on the dispensing label even if it was missing in the prescription ( $n=364 ; 89.6 \%)$. Patients were sent back to prescriber to clarify DRPs $(n=14 ; 3.4 \%)$ in a few instances, mostly when they encountered ambiguous names of medicines that were illegible $(n=8 ; 1.9 \%)$, when frequencies of medicines were missing $(n=3 ; 0.7 \%)$, and when too high drug doses were prescribed $(n=3 ; 0.7 \%)$. Pharmacists refused to dispense drugs on nine occasions $(n=9 ; 2.2 \%)$ which were related to outdated prescriptions, and missing prescriber credentials on prescription. Pharmacists also made every effort to resolve issues by discussing with patients $(n=8 ; 1.9 \%)$, checking with recent written medical histories of patients $(n=4 ; 0.9 \%)$, and through discussion with fellow pharmacists $(n=5 ; 1.2 \%)$ which is acceptable if DRPs are resolvable beyond doubt through these measures. It is noteworthy that none of the community pharmacists consulted written references or decision support software in this study possibly due to the unavailability of such resources. Ezeuko et al., too reported this observation in resource limiting settings [3].

To our knowledge, there are no studies that have focused on the prevalence of a wide-range of DRPs in prescriptions brought for dispensation to community pharmacies, the ability of the community pharmacists to detect such DRPs, and their practices when resolving these DRPs using prescription review and direct observation methods as in our study. However, there are some limitations to our study which needs to be considered. We carried out the study only in one community pharmacy in Sri Lanka. Therefore, our sample does not represent the total study population of this country. However, this study provides evidence on a very important but seldom researched area. A direct observation was done to assess if pharmacists identified and took corrective action for DRPs, but it is possible that a 'Hawthorne Effect'. Nevertheless, it is concluded that behavior of observes are seldom affected by direct observation [5].

\section{Conclusions And Recommendations}

This study found that DRPs exist in prescriptions dispensed in outpatient prescriptions and community pharmacists were able to identify and resolve some of them. Community pharmacists identified drug duplication, and wrong doses, frequencies, dosage forms and durations of drugs written on prescriptions. However, they overlooked DRPs related to missing information and drug interactions. Pharmacists also resolved most DRPs using self-judgement. Patients were sent back to prescriber to clarify DRPs mostly when drug names were not clear, when frequencies of drugs were missing, and when too high drug doses were prescribed. Pharmacists also refused to dispense drugs for outdated prescription, and when prescriber details were missing. Pharmacists were also observed discussing with patients, checking on recent written patient histories, and consulting fellow pharmacists to resolve DRPs. Unfortunately, references material or decision support software were unavailable for pharmacists to refer.

It is recommended that pharmacists are continuously trained on conducting a preliminary prescription review before dispensing of prescriptions to identify DRPs which may potentially harm patients. They should also be trained to assertively communicate with prescribers to resolve harmful DRPs instead of speculating possibilities of ambiguous prescriptions. Dispensing pharmacists must be provided at least with software to check for drug interactions, and with decision support systems where possible. Given the high prevalence of DRPs in prescriptions, these recommendations will help ensure patient safety.

\section{Abbreviations}

PCNE: The Pharmaceutical Care Network Europe; USA: United State of America; SLMC: Sri Lanka Medical Council; SPSS: Statistical Package for the Social Sciences

\section{Declarations}

Ethics approval and consent to participate

Ethical approval was obtained from the Ethics Review Committee of the University of Sri Jayewardenepura (Ref: B.Pharm/08/17). Approval was also obtained from the Head office of the community pharmacy chain to conduct this study. Written informed consent was obtained from study participants.

Consent for publication

All authors consent for publication.

Availability of data and materials 
The datasets used and/or analysed during the current study are available from the corresponding author on reasonable request.

Competing interests

The authors declare that they have no competing interests.

Funding

The author(s) received no financial support for this research.

Authors' contribution

TSJ Janani: Data curation, Formal analysis, Writing - original draft

R Risla: Data curation, Formal analysis

LGT Shanika: Conceptualization, Formal analysis, Methodology, Supervision, Writing - original draft, reviewing, and editing

N.R Samaranayake: Conceptualization, Formal analysis, Methodology, Supervision, Writing -reviewing, and editing

Acknowledgements

The authors would like to acknowledge the Chairman, State Pharmaceutical Corporation, Sri Lanka of the community pharmacy chain to conduct this study. Also, we would acknowledge the manager of the pharmacy outlet, and the community pharmacists who participated in the study.

\section{References}

1. Adepu R, Adusumilli PK. Assessment of drug-related problems in patients with chronic diseases through health status survey in a south Indian rural community setting. Indian Journal of Pharmaceutical Sciences. 2016;78(4):537-542.

2. Alsulami Z, Conroy S, Choonara I. Medication errors in the Middle East countries: A systematic review of the literature. European Journal of Clinical Pharmacology. 2013;69(4): 995-1008.

3. Amaka EY, Sunday NO, Chukwuanugo ON, John UO, Emmanuel IE, Mathew OJ. Drug related problem (DRP) identification and resolution among healthcare professionals working in the emergency and intensive care units of a Nigerian teaching hospital. World Journal of Pharmacy and Pharmaceutical Sciences. 2015;4(5):47-60.

4. Australian Medicines Handbook. Adelaide: Australian Medicines Handbook Pty Ltd; 2011.

5. Centers for Disease control and Prevention. Evaluation Briefs \#16. Data Collection Methods for Program Evaluation: Observation: Available from https://www.cdc.gov/healthyyouth/evaluation/pdf/brief16.pdf

6. De Silva KIM, Parakramawansha KPRC, Sudeshika SHT, Gunawardhana CB, Sakeena MHF. Investigation of medication errors: A prescription survey from Sri Lanka. Tropical Journal of Pharmaceutical Research. 2015;14(11): pp. 2115-2120.

7. Europe, P. C. N. Classification for Drug Related Problems. The PCNE Classification V8. 01. Disponible en: http. 2017, June 15

8. Gandhi TK, Weingart SN, Borus J, Seger AC, Peterson J, Burdick E. Adverse drug events in ambulatory care. New England Journal of Medicine. 2003;348(16), 1556-1564.

9. Hammerlein A, Griese N, Schulz M. Survey of drug related problems identified by community pharmacies. Annals of Pharmacotherapy. 2007;41(11), 18251832.

10. Jamal I, Amin F, Jamal A, Saeed A. Pharmacist's interventions in reducing the incidences of drug related problems in any practice setting. International current pharmaceutical journal. 2015;4(2), 347-352.

11. Joint Formulary Committee. British National Formulary 70. London: BMJ Group and Pharmaceutical Press. September 2015 - March 2016.

12. Kjeldsen LJ, Nielsen TRH, Olesen C. Investigating the relative significance of drug-related problem categories. 2017;5(2), 31.

13. Kováčová B, Ďurišová A. Drug-related problems identified by pharmacist-led medication review in Slovak hospitalised patients. Die Pharmazie. 2016.71(9), 548-551.

14. Krähenbühl-Melcher A, Schlienger R, Lampert M, Haschke, M, Drewe J, Krähenbühl Drug related problems in hospitals. a review of the recent literature. Drug Safety. 2007;30(5), 379-407.

15. Mamunuwa GN, Dorabawila BM. The need for clinical pharmacy services in Sri Lanka; a study based on the prevalence of drug related problems in two hospitals. International Journal of Scientific and Research Publications. 2014;4(9), 2250-3153.

16. Mamunuwa N, Jayamanne S, Coombes J, De Silva A, Lynch C, Wickramasinghe D. Drug related problems among patients with diabetes; a descriptive analysis of data from an urban hospital in Sri Lanka. Paper presented at the $17^{\text {th }}$ International Postgraduate Research Conference, Colombo, Sri Lanka. 2016, December 8-9.

17. Medscape Pharmacists. Available from: https://www.medscape.com/pharmacists.

18. Nicolas A, Eickhoff C, Griese-Mammen N, Schulz Drug related problems in prescribed medicines in Germany at the time of dispensing. Interntional Journal of Clinical Pharmacy. 2013;35(3), 476-482. 
19. Paulino El, Bouvy ML, Gastelurrutia MA, Guerreiro M, Buurma H. Drug related problems identified by European community pharmacists in patients discharged from hospital. Pharmacy world and science. 2004;26(6), 353-360.

20. Perera DMP, Coombes JA, Shanika LGT, Dawson A, Lynch C, Mohamed F. Opportunities for pharmacists to optimise quality use of medicines in a Sri Lankan hospital: An observational, prospective, cohort study. Journal of Pharmacy Practice and Research. 2017;47(2), 121-130.

21. Rathish D, Bahini S, Sivakumar T, Thiranagama T, Abarajithan T, Wijerathne, B. Drug utilization, prescription errors and potential drug-drug interactions: an experience in rural Sri Lanka. BMC Pharmacology and Toxicology. 2016;17(1), 27.

22. Sakeena MHF, Bennett AA, McLachlan AJ. The Need to Strengthen the Role of the Pharmacist in Sri Lanka: Perspectives. Pharmacy;2019;7(2), 54.

23. Salmasi S, Khan TM, Hong YH, Ming LC, Wong TW. Medication Errors in the Southeast Asian Countries: A Systematic Review. PLoS One. 2015;10(9).

24. Shanika LGT, Jayamanne S, Coombes J, Coombes I, Wijekoon CN. Adverse Drug reactions and associated factors in a cohort of Sri Lankan patients with non-communicable chronic diseases. Pharmaceutical Journal of Sri Lanka. 2016;6, 2-8.

25. Shanika LGT, Jayamanne S, Wijekoon CN, Coombes J, Perera D, Mohamed F. Ward-based clinical pharmacists and hospital readmission: a nonrandomized controlled trial in Sri Lanka. Bulletin of the World Health Organization. 2018;96(3), 155-164

26. Thirumagal M, Ahamedbari MAR, Samaranayake NR, Wanigatunge CA. Pattern of medication errors among inpatients in a resource-limited hospital setting. Postgraduate medical journal. 2017;93(1105), 686-690.

27. Westerlund T, Almarsdóttir AB, Melander A. Drug-related problems and pharmacy interventions in community practice. International Journal of Pharmacy Practice. 1999;7(1), 40-50.

28. WHO [World Health Organization] (1994). The role of the pharmacist in the health care system; Report of a WHO Consultative group, New Delhi, India 1988 and Report of a WHO meeting, Tokyo, Japan 1993" [online] Available at: http://apps.who.int/medicinedocs/en/d/Jh2995e/ (Accessed on 12th May 2018)

\section{Figures}

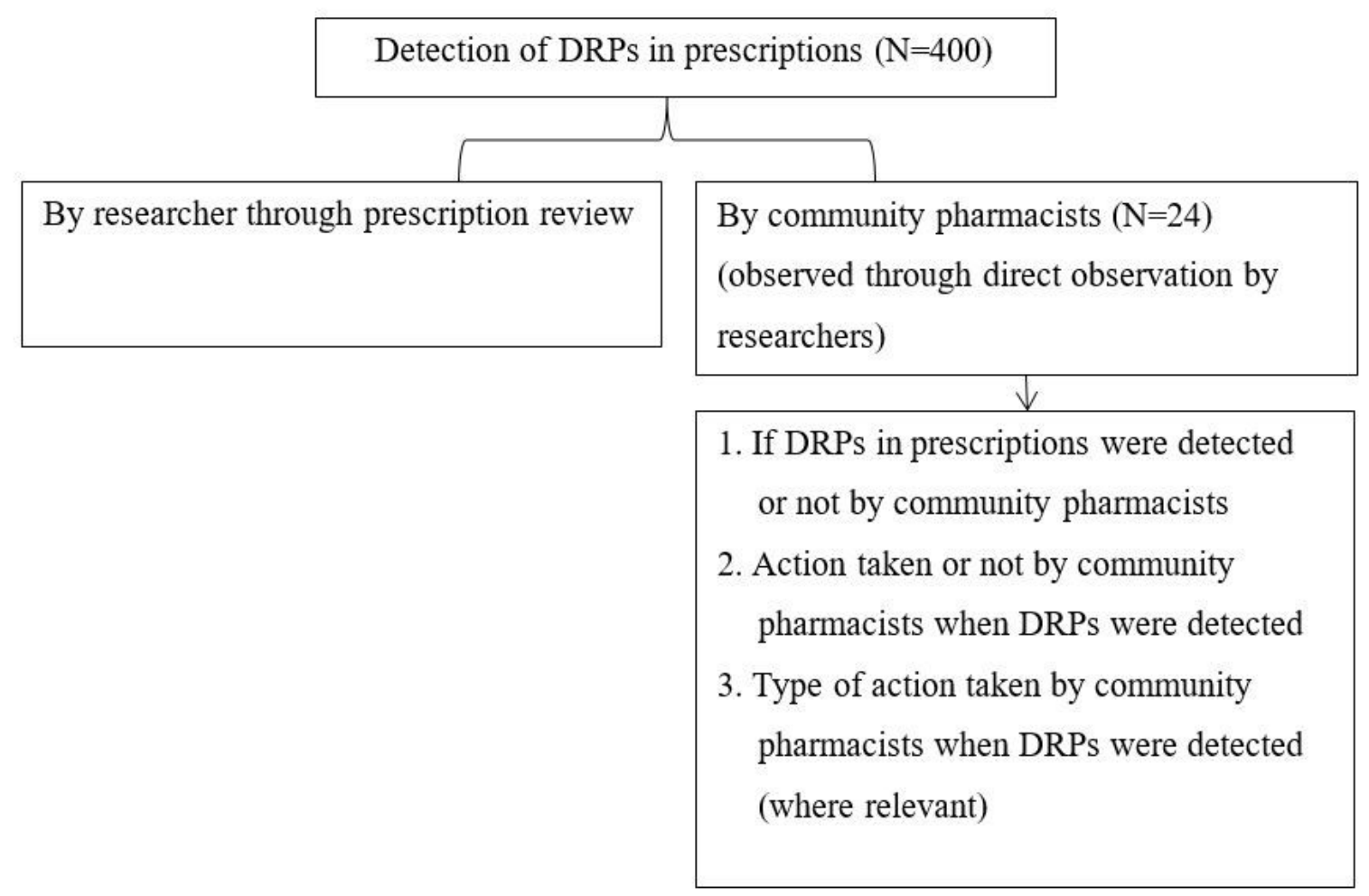

Figure 1

Study process 
DRPs identified by community pharmacists $(N=441)$

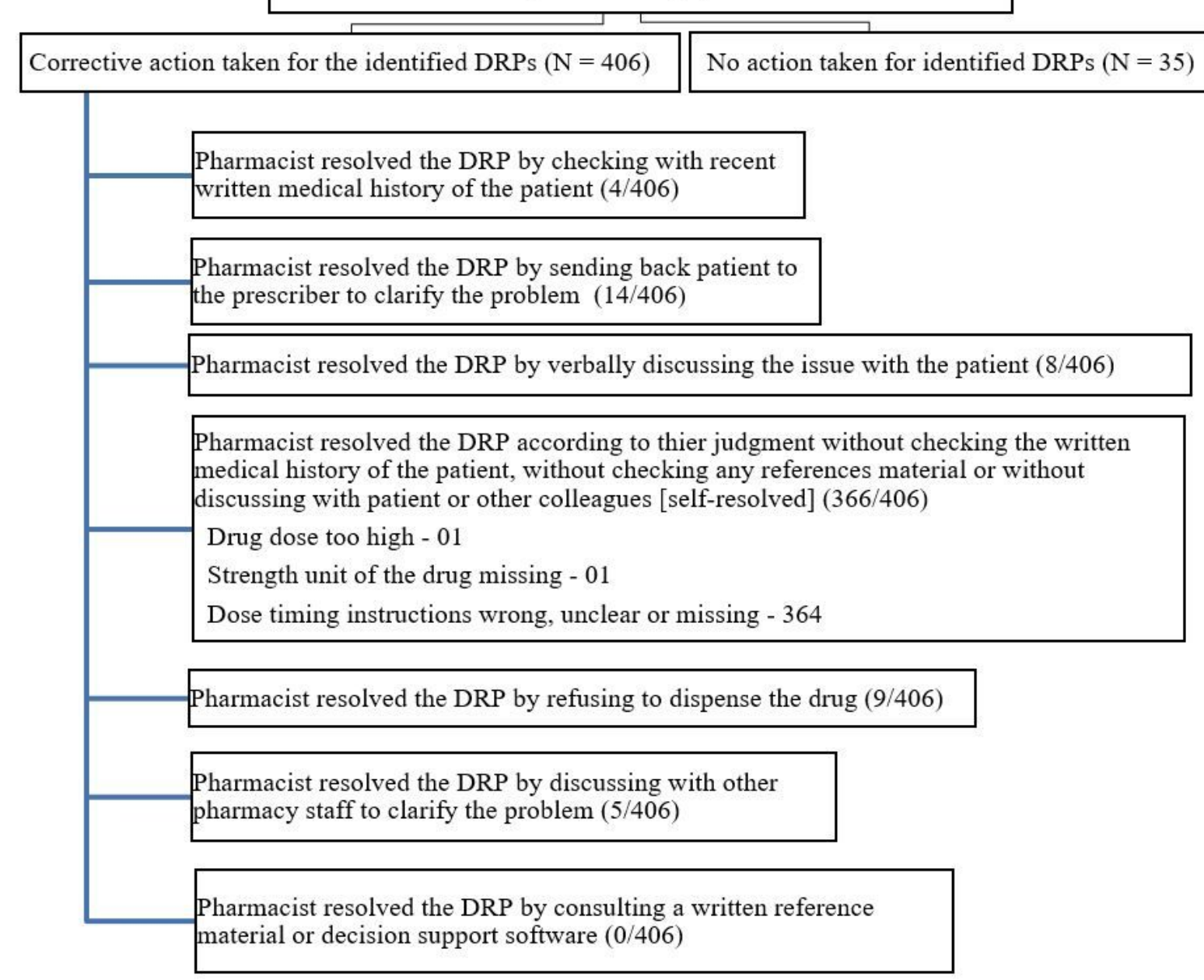

Figure 2

Summary of corrective actions taken by community pharmacists for DRPs identified by them

\section{Supplementary Files}

This is a list of supplementary files associated with this preprint. Click to download.

- Supplementaryfile.docx 